\title{
BUSCA DE OPORTUNIDADES: O CAMINHO DA COMPETITIVIDADE
}

\author{
Andrea Lago da Silva \\ Núcleo de Estudos Estratégicos/PPGEP/UFSC \\ Cristiano J. Castro de Almeida Cunha \\ Núcleo de Estudos Estratégicos/PPGEP/UFSC
}

O aumento da dinâmica da competição a nível mundial tem levado as empresas a se preocuparem mais com a busca de novas oportunidades. Essa tendência deve crescer em importância, na medida em que os mercados internacionais tornem-se mais dependentes e as fronteiras ao livre comércio diminuam. Este artigo discute alguns modelos e aspectos normativos da busca de oportunidade. Parte-se do pressuposto que o processo de busca de oportunidade pode e deve ser organizado de forma sistemática.

Palavras-chaves: busca de oportunidade, estratégia empresarial, fontes de oportunidade, competitividade.

\section{Introdução}

O interesse pela busca de oportunidades tem crescido muito nos últimos anos, tanto entre os acadêmicos quanto entre os executivos. Algumas razões importantes que podem explicar esse fenômeno são: primeiro, a recessão a nível mundial que induz as empresas a buscarem, com mais afinco, novas formas de atuação que lhes permitam superar a crise. Segundo, a globalização dos mercados, que tem aumentado a complexidade e a dinâmica do ambiente externo às organizações, gerando a necessidade de um maior monitoramento das mudanças que podem afetá-las positiva ou negativamente. A este respeito é importante lembrar a tese proposta por LEVITT (1983) de que as empresas que atuam no mercado internacional só poderão sobreviver adotando estratégias globais. Isto gera um alto grau de complexidade no processo de gerenciamento das oportunidades. Em terceiro lugar, tem ocorrido nos últimos anos, uma disseminação do uso das estratégias de nicho, que implicam em um monitoramento mais detalhado e sistemático do ambiente da empresa. Isso tudo, aliado ao fato de que a competição entre as empresas tem se tornado mais acirrada, faz com que essas se preocupem mais em explorar tanto as oportunidades internas para o aumento da qualidade e produtividade, quanto as oportunidades externas, encontradas no seu ambiente.

O conceito de oportunidade engloba, portanto, duas categorias: oportunidades internas e oportunidades externas. As internas se referem às situações que ocorrem no 
ambiente interno da organização e que, se bem exploradas, podem aumentar sua competitividade. Já as externas são situações do ambiente externo à organização que podem, potencialmente aumentar sua vantagem competitiva em relação às outras organizações. A partir desta visão, uma das principais atividades das empresas que atuam com uma orientação estratégica em ambientes competitivos é a busca de oportunidades.

A busca de oportunidades tem desempenhado um papel fundamental no processo de crescimento empresarial e sua própria natureza tem se modificado. O processo de busca que, antes, estava associado apenas à figura do empreendedor (MINTZBERG, 1973) desenvolveu-se no sentido de englobar um conjunto de ferramentas de prospecção e análise sistemática das forças ambientais não controladas pela organização. O conceito de oportunidade externa refere-se às "...forças ambientais, incontroláveis pela empresa, que podem favorecer a sua ação estratégica, desde que conhecidas e aproveitadas satisfatoriamente enquanto perduram..." (OLIVEIRA, 1989).

O objetivo deste artigo é discutir algumas das principais questões relacionadas com os aspectos normativos da busca de oportunidades.

\section{O Problema de Busca de Oportunidades}

Para DE BONO (1989), "antes de chegar a existir, todo negócio é uma oportunidade que alguém percebeu", ou seja, a oportunidade refere-se a uma possibilidade de utilização de recursos (sejam estes humanos, materiais ou ainda conhecimentos) com o objetivo de aproveitar uma chance para a criação de uma nova atividade, que traga retorno ao indivíduo que a utilizou.

Uma das definições mais simples, e até talvez a mais clara, seja a de OLIVEIRA (1989) que define oportunidades como forças ou eventos ambientais, que são incontroláveis pela empresa e que podem favorecer sua ação estratégica, desde que conhecidos e aproveitados satisfatoriamente enquanto existirem.

A partir desta definição, pode-se analisar a relação entre a busca de oportunidades e o processo de Planejamento Estratégico. Normalmente, nas metodologias utilizadas para a execução deste processo , a análise externa é a etapa na qual se "...verifica as ameaças e oportunidades que estão no ambiente da empresa e as melhores maneiras de evitar ou usufruir destas situações" (OLIVEIRA, 1989).

Segundo CUNHA (1991), as etapas do Planejamento Estratégico podem ser descritas conforme a figura 1.

As oportunidades, nesse modelo, são consideradas como situações externas à organização, que podem influenciar positivamente nos seus fatores-chaves de sucesso. Assim como CUNHA (1991), grande parte dos autores de Planejamento Estratégico consideram que a busca de oportunidades se relaciona com fatores externos à organização.

Fugindo a essa tendência, DE BONO (1989) expande um pouco mais o escopo da busca de oportunidades. Ele afirma que "...oportunidade é algo que você ainda não sabe que quer realizar, mas é capaz de fazê-lo". Este conceito mostra a intenção do 
autor em analisar como os indivíduos podem perceber, mesmo nas atividades rotineiras do dia-a-dia , novas habilidades, processos ou maneiras de iniciar ou dinamizar atividades numa organização ou fora dela. De Bono introduz aí, o conceito de oportunidades interna e externa, tratando mais especificamente destas quando analisa alguns aspectos da busca de oportunidades.

De Bono argumenta que, para pensar em oportunidades deve-se partir de algum aspecto da organização ou do ambiente que a cerca. Para isso, ele propõe uma "lista de pontos de partida" (DE BONO, 1989), entre os quais encontram-se os ativos disponíveis, a sinergia (entre as organizações e o ambiente ou entre o indivíduo e o seu negócio), as áreas de fraqueza e de força e as áreas sensíveis a idéias (conhecidas também como ASI).

As áreas de fraqueza e áreas de força são justamente os pontos fracos e fortes, apresentados pela organização e as oportunidades daí advindas. Um ponto forte "é a diferenciação conseguida pela empresa que lhe proporciona uma vantagem operacional no ambiente empresarial..." e ponto fraco "é uma situação inadequada da empresa que lhe proporciona uma desvantagem operacional no ambiente empresarial" (OLIVEIRA, 1989).

Outro aspecto considerado "ponto de partida" por De Bono são as "áreas sensíveis a idéias" (ASI), definidas como áreas da empresa para as quais se deve olhar com o objetivo de descobrir uma oportunidade. O autor argumenta que até uma "área de fraqueza" (da qual falamos anteriormente) pode ser focalizada e tornar-se uma ASI.

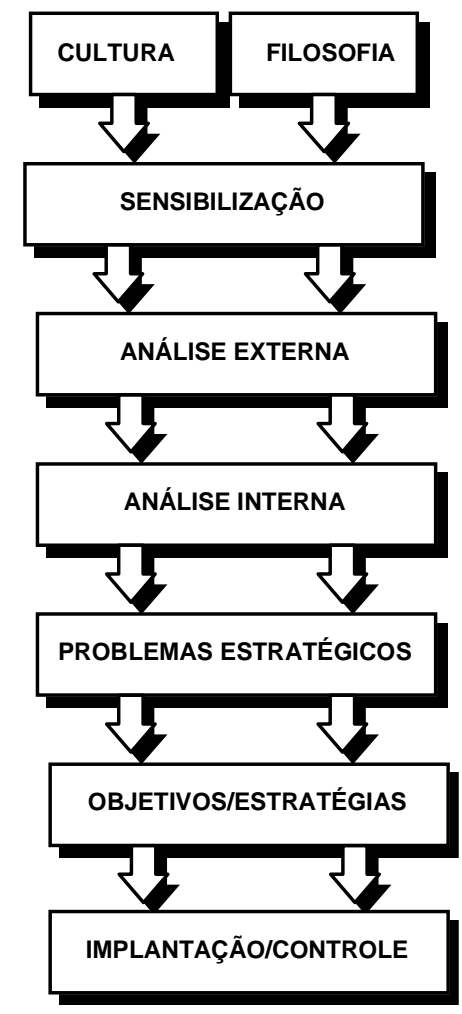

Figura 1: Planejamento Estratégico

Fonte: CUNHA (1991) 
Uma abordagem complementar à de De Bono, para o problema da busca de oportunidades, é a apresentada por Peter Drucker. DRUCKER (1987) argumenta que, "o empreendedor vê a mudança como norma e como sendo sadia. Geralmente, ele não provoca a mudança por si mesmo. Mas, e isso define o empreendedor e o empreendimento, o empreendedor sempre está buscando a mudança, reage a ela, e a explora como sendo uma oportunidade". Este autor considera que o indivíduo que busca oportunidades deve estar constantemente preocupado com a inovação.

A inovação é conceituada por DRUCKER (1987) como um processo sistemático que consiste na busca deliberada e organizada de mudanças (sejam elas sociais, econômicas ou tecnológicas) e na análise permanente e sistemática das oportunidades que tais mudanças podem oferecer.

Para DRUCKER (1987), "não existe algo chamado recurso até que o homem encontre um uso para alguma coisa na natureza e assim o dote de valor econômico". Assim também são as oportunidades e as inovações, até que um indivíduo ou organização perceba-as e tire proveito delas, essas são apenas fontes potenciais de lucro ou vantagem competitiva.

$\mathrm{O}$ autor enumera sete fontes de oportunidades. As quatro primeiras ligadas a fatores relacionados à organização e ao setor no qual está inserida. As três seguintes originárias de mudanças fora da organização ou do setor. As fontes de oportunidades citadas por DRUCKER (1987) são:

- o inesperado - seja um fracasso, um sucesso ou qualquer evento que não tenha sido previsto pela organização;

- a incongruência - entre a realidade como é e como deveria ser;

- a inovação como necessidade de um processo;

- mudanças na estrutura do setor industrial ou na estrutura do mercado, totalmente imprevista no momento em que ocorre.

- mudanças demográficas (populacionais, por exemplo);

- mudanças na percepção, disposição e significado;

- conhecimento novo, podendo ser científico ou não-científico.

Definidas as fontes de oportunidades, vejamos o "como" buscar oportunidades.

\section{A Busca de Oportunidades}

A busca de oportunidades não pode se dar ao acaso. Isto torna a tarefa ineficiente quanto a seus resultados e muito dispendiosa em recursos financeiros e tempo. É necessário que a busca se dê de forma sistematizada. O processo sistemático de busca de oportunidades é um conjunto de etapas definidas para serem utilizadas organizações que procuram, de alguma maneira, organizar o exercício da busca de oportunidades e torná-lo permanente.

A adoção ou não de um processo sistemático de busca de oportunidade por uma empresa está relacionada com o estilo do executivo. É, portanto, conveniente se conhecer alguns destes estilos e relacioná-los com os obstáculos à busca sistemática de oportunidades como propostos por DE BONO (1989). Partindo da suposição de que 
"...o estilo de um executivo determina não o que ele é capaz de fazer, mas o que ele vai se permitir fazer", o autor define quatro tipos de estilo:

- o maquinista de trem -este pode ser definido como o "zelador" das normas e estratégias já definidas. É do tipo que quando tem que enfrentar situações novas, fora da sua "rota", pede ajuda;

- o médico - é o tipo de executivo especialista em resolver problemas, controlar informações vindas de diversas áreas da empresa, detectar possíveis problemas e recomendar soluções.

- o lavrador - é o indivíduo que tem idéias progressistas e, se tem idéias, procura oportunidades. Porém, faz isso apenas no seu campo de atuação ou no seu ramo de negócio;

- o pescador - é o executivo que assume riscos. Porém, conta sempre com o apoio de ferramental necessário para conseguir seu intento. É o tipo de indivíduo que, se posicionado corretamente, procura e persegue qualquer oportunidade que apareça.

Pode-se alinhar os quatro estilos de executivos em um continuum e relacioná-los com a propensão ao risco, criatividade e propensão à busca de oportunidades (Figura 2).

A identificação do estilo do executivo é importante pois, como ressalta DE BONO (1989), "é absurdo recrutar homens inteligentes para uma empresa, e então culpá-los por agir inteligentemente".

\begin{tabular}{|c|c|c|c|}
\hline $\begin{array}{c}\text { Estilos de } \\
\text { executivos }\end{array}$ & $\begin{array}{c}\text { Propensão } \\
\text { em relação ao } \\
\text { risco }\end{array}$ & Criatividade & $\begin{array}{c}\text { Propensão à } \\
\text { busca de } \\
\text { oportunidade }\end{array}$ \\
\hline $\begin{array}{c}\text { Maquinista } \\
\text { de trem }\end{array}$ & Mínima & Mínima & Mínima \\
\hline Médico & Baixa & Baixa & Baixa \\
\hline Lavrador & Média & Média & Média \\
\hline Pescador & Alta & Alta & Alta \\
\hline
\end{tabular}

Figura 2 - Continuum de Estilos de Executivos

Outro aspecto importante do modelo de DE BONO (1989) é a série de obstáculos que podem ser colocados à busca de oportunidades. Entre eles encontram-se:

- os organizacionais - como os assuntos urgentes do dia-a-dia, o estilo de administração do tipo: "o patrão sabe tudo", falta de tempo, disponibilidade de recursos e até pensadores imaginativos; pouca propensão a assumir riscos e problemas com lucro a curto prazo;

- os ambientais - como a relação com sindicatos, prescrições legais, governamentais, burocráticas e controles de impostos e preços. Também são 
consideradas nesta lista as pressões ecológicas, o porte do mercado e a falta de capital de risco;

- os relacionados a pessoal - como dificuldade em avaliar oportunidades criadas; preferência por atitudes reativas ao invés de proativas; gosto por uma vida tranqüila; falta de técnica, motivação financeira, encorajamento ou confiança; visão tradicional e ausência de enfoque na busca de oportunidades.

Estes obstáculos variam de acordo com o tipo de empresa, seu ambiente, seu negócio e até com o ciclo de vida de seus produtos e sua história no mercado.

\section{Espírito Empreendedor e Busca de Oportunidades}

Quando se fala em oportunidade, vários autores, entre eles BURGELMAN (1982), ROSS (1987), DRUCKER (1987), PINCHOT III (1989) e CHRISTENSEN (1990), destacam o papel da abordagem empreendedora e sugerem a importância do 'intrapreneur' para as organizações.

O empreendedor ('entrepreneur') é definido por ROSS (1987) como o indivíduo que inicia seu próprio negócio e, como tal, assume todos os riscos relacionados a esse. Segundo DRUCKER (1987), o empreendedor ou o indivíduo/organização que age sob a abordagem empreendedora (entrepreneurship) é aquele que vê a mudança como norma e como sendo sadia. Em geral, esses indivíduos ou organizações não provocam a mudança por si mesmos, mas estão sempre buscando-a, reagindo a ela e explorandoa como sendo uma oportunidade.

Outro conceito importante quando se trata o tema "oportunidade" é o 'intrapreneur', ou seja, o indivíduo que atua de forma empreendedora, só que dentro de uma organização já estabelecida, normalmente na posição de executivo. PINCHOT III (1989) afirma que ser um 'intrapreneur' é um estado de espírito do indivíduo que assume a responsabilidade pelas inovações de qualquer espécie dentro de uma organização.

O que diferencia o 'intrapreneur' do 'entrepreneur' (empreendedor) é o fato de o primeiro estar enquadrado em uma organização já estabelecida e o segundo ser aquele indivíduo que cria sua própria organização. Ambos têm em comum, e isso justifica sua importância neste estudo, a orientação para a busca sistemática de oportunidades, seja no dia-a-dia de uma organização já estabelecida ou no momento em que se cria uma nova organização.

Conforme BURGELMAN (1982), o comportamento empresarial, orientado pela abordagem ou pelo espírito empreendedor tem como principal contribuição o desenvolvimento da capacidade da organização em enfrentar turbulências ambientais. Essa capacidade refere-se também à criação de novos nichos de mercado e ao desenvolvimento de atividades que dêm suporte às estratégias da organização.

\section{A Buca de Oportunidades a Nível Gerencial}


Nesse momento, é conveniente tratar as diferenças do problema da busca de oportunidade em um empreendimento existente com relação a um novo empreendimento.

DRUCKER (1987) afirma que, "...uma empresa existente...sabe como administrar, mas precisa aprender como ser empreendedora e como inovar...E o negócio novo de risco precisa aprender como ser empreendedor e como inovar, mas, acima de tudo, aprender como administrar". Ou seja, numa empresa estruturada há necessidade de incentivar e preservar o espiríto de inovação ou a busca constante por oportunidades. Já em uma empresa recém-criada, além dessa atividade, ela necessita aprender a administrar as tarefas rotineiras, para que possa se estruturar e crescer. Percebe-se que a tarefa que cabe ao indivíduo que inicia um negócio é um pouco mais árdua.

Tratando deste tema, DEGEN (1989) postula sobre como criar um negócio próprio e ser bem sucedido. A primeira etapa proposta por ele é justamente a identificação de oportunidades e neste caso, o autor argumenta que dois aspectos são essenciais: a predisposição para tal atividade (através da observação e avaliação do negócio) e a criatividade (pela qual ele somatiza as observações em forma de empreendimento). Para identificar oportunidades, DEGEN (1989) propõe oito procedimentos:

- Identificação de necessidades;

- Observação de deficiências;

- Observação de tendências;

- Derivação da ocupação atual;

- Procura de outras aplicações;

- Exploração de hobbies;

- Lançamento de moda; e

- Imitação do sucesso alheio.

Estas fórmulas parecem extremamente simples, mas o autor acrescenta a elas a necessidade de se manter a objetividade para com a idéia original sobre a oportunidade de negócio que se tem.

\section{A Busca de Oportunidades dentro do Contexto Estratégico}

SINGH et al. (1986) argumentam que a formulação das estratégias empresariais é baseada no entendimento que os administradores da alta cúpula gerencial têm tanto dos pontos fortes e fracos da organização quanto das oportunidades apresentadas pelo ambiente no qual a mesma está inserida. Como as estratégias devem contribuir para a obtenção de um grau aceitável de adaptação ao ambiente, o reconhecimento das oportunidades existentes no mesmo, apresenta-se como uma atividade fundamental.

No que se refere à sua relação com a adaptação organizacional, a busca de oportunidades encontra respaldo na perspectiva analítica da escolha estratégica (MILES \& SNOW, 1978). Segundo esta perspectiva, a busca de solução do Problema Empresarial passa pela busca de oportunidades. Neste processo, a coalizão dominante 
tem o papel de perceber os fatores relevantes para a organização e determinar o tipo de atitude que a mesma tomará acerca desses fatores.

A busca de oportunidades é um elemento-chave para a elaboração de estratégias mais coerentes com o ambiente no qual a empresa está inserida. A capacidade de uma empresa pensar estratégicamente é um elemento vital, segundo CHRISTENSEN (1990), pois há necessidade de que ela desenvolva sua capacidade cognitiva acerca do que é de fato uma oportunidade e quando essa é de fato interessante para a organização.

\section{Conclusões}

Este artigo pretendeu realizar um levantamento dos principais textos sobre a busca de oportunidades.

Como se pode observar, essa é uma atividade que procura, seja no ambiente interno ou externo às organizações, fatores ou situações que podem melhorar o seu desempenho.

Como foi sugerido por diversos autores, entre eles DRUCKER (1987), DE BONO (1989) e DEGEN (1989), é preciso que as organizações atuem no sentido de buscar continuamente oportunidades. Essas oportunidades, muitas vezes, estão relacionadas com inovações a nível gerencial e produtivo, tendo como objetivo a adaptação mais fácil ao ambiente no qual as organizações estão inseridas.

A atividade de busca de oportunidades é, num primeiro momento, responsabilidade da cúpula gerencial das organizações, ou seja, dos fundadores (se ainda estiverem presentes) e dos executivos.

Nesse sentido, a cúpula gerencial deve procurar atuar de maneira proativa, de acordo com uma abordagem empreendedora, o que no caso dos executivos implicaria em torná-los verdadeiros 'intrapreneurs'.

Os obstáculos para sistematizar a busca de oportunidades numa organização sempre existem, mas é necessário que se procure superá-los, tendo em vista os objetivos de inovação e competitividade empresariais.

\section{Referências Bibliográficas:}

BURGELMAN, R.A.: "Corporate Entrepreneurship and stategic manangement: insights from a process study". Management Science, v.29, n.12, p.1349-1364, 1982.

CHRISTENSEN, P.S.: Strategy, opportunity identification, and entrepreneurship. A study of the entrepreneurial opportunity identification process. University Press, Denmark:Aarhus , 1990.

CUNHA, C.J.C.A.: Planejamento Estratégico. Programa de Pós-Graduação em Engenharia de Produção, UFSC, Manuscrito, 1991. 
DE BONO, E.: Oportunidades: um manual para a busca de melhores oportunidades nos negócios. Vértice, São Paulo, 1989.

DEGEN, R.J.: "Idéias valem mais do que capital". Pequenas Empresas Grandes Negócios, Rio de Janeiro, ano I, n.8, p.19-21, set/1989.

DEGEN,R.J.: $\mathbf{O}$ empreendedor. Fundamentos da iniciativa empresarial. 3a.ed.. McGraw-Hill, São Paulo, 1989.

DRUCKER, P.F.: Inovação e espírito empreendedor. Prática e princípios. 2a.ed.. Pioneira, São Paulo, 1987.

LEVITT, T.: "The globalization of markets". Harvard Business Review, v.61, 1983.

MILES, R.E. \& SNOW, C.C.: Organizational strategy, structure and process. Mc Graw Hill, New York, 1978.

MINTZEBERG, H.: "Strategy-making in three modes". California Management Review, v.16, n.2, 1973. p. 44-53.

OLIVEIRA, D.P.R.: Planejamento estratégico. Conceitos, metodologia e prática. 4a.ed.. Atlas, São Paulo, 1985.

PINCHOT III, G.: Intrapreneuring - Por que você não precisa deixar a empresa para tornar-se um empreendedor. Harbra, São Paulo, 1989.

ROSS, J.: "Corporations and entreprenuers: Paradox and opportunity". Business Horizons, v.30, n.4, 1987.

SINGH, J. et al.: "Organizational change and organizational mortality". Administrative Science Quarterly, v.31, p.587 -611, 1986.

\section{THE SEARCH OF OPPORTUNITIES: THE WAY TO COMPETITIVENESS}

ABSTRACT - The growth of dinamic world competition has taken the organizations to have more interest in the search of new opportunities. This tendency must grow as international markets become more dependent and the boundaries of these free trades decrease gradually. This paper discusses some models and normative aspects in search of opportunities. This process could and must be organized in a sistematic way.

Key-words: search of opportunities, entrepreneurial strategy, sources of opportunities. 